\title{
Effect of the particle-size distribution variability on the SWCC predictions of coarse-grained materials
}

\author{
Roberto Alves ${ }^{1, *}$, Gilson de F.N. Gitirana Jr. ${ }^{1}$, and Sai K. Vanapalli ${ }^{2}$ \\ ${ }^{1}$ Universidade Federal de Goiás, School of Civil and Environmental Engineering, Goiânia, Brazil \\ ${ }^{2}$ University of Ottawa, Department of Civil Engineer, Ottawa, Canada
}

\begin{abstract}
The particle-size distribution (PSD) is the key information required by several models for prediction of the soil-water characteristic curve (SWCC). The performance of these models has been extensively investigated in the literature; however, limited studies have been undertaken with respect to the uncertainty associated with the SWCC predictions resulting from the variability in the PSD. This study aims to investigate the influence of the variability of the PSD in the prediction of SWCCs using five different models applied to three different glass beads (GBs). The PSD curves were determined by sieve analysis, laser diffraction, and image analysis. The various testing procedures were statistically evaluated to understand the influence of variability of the PSD in terms of the coefficient of uniformity $\left(C_{\mathrm{U}}\right)$ and de size of particles corresponding to $10 \%$ in the PSD $\left(D_{10}\right)$. For each prediction model, a combination of PSD curves and their coefficient of variation were used to estimate the SWCCs. Both the $C_{\mathrm{U}}$ and $D_{10}$ proved to have a strong relationship with the predicted SWCCs. The $C_{\mathrm{U}}$ appears to influence more the residual suction prediction while the $D_{10}$ seems to have a major role for the transition and residual stages.
\end{abstract}

\section{Introduction}

There are many models available in the literature to predict or estimate the soil-water characteristic curve (SWCC) such as the Arya \& Paris (1981) [1]; Haverkamp \& Parlange (1986) [2]; Fredlund \& Xing (1994) [3]; Fredlund et al. (2002) [4]; Aubertin el al. (2003) [5]; Tuller \& Or (2005) [6]; Jaafar \& Likos (2011) [7]; Wang et al. (2017) [8] and Alves et al. (2020) [9]. Several of these models attempt to establish a correlation between their input variables and geotechnical parameters, which include the particle-size distribution (PSD), void ratio, organic matter content, dry density, specific gravity, coefficient of uniformity, liquid limit, and specific surface area.

The performance of the SWCC prediction models is influenced by variables such as the particle shape, mineralogical composition, and arrangement of the particles. Also, hysteresis between wetting and drying cycles are mainly due to the differences of the receding and advancing contact angles, the "ink-bottle" effect and entrapped air (Fredlund et al. 2012 [10], Lu \& Likos 2004 [11]). The water may contain dissolved salts which affects its surface tension, which is also dependent on the temperature (Vargaftik et al. 1983 [12], Karagunduz et al. 2001 [13], Sghaier et al. 2006 [14]). In addition, the presence of organic matter influences the interaction forces mainly for the fine fractions (Gupta \& Larson 1979 [15], Jong et al. 1983 [16], Liu et al. 2014 [17]). Thus, considering that these aspects act simultaneously to determine the soil suction, it is clear the difficulty involved in predicting the SWCC.

There are several studies that present investigation on the variability of the SWCC. Zapata et al. (2000) [18] investigated the uncertainty of direct suction measurements and that associated with the predicted SWCC. The authors found that the influence of the operator in the measurement of the SWCC was greater than that associated with prediction models based on index properties. Likos et al. (2013) [19] studied the uncertainty of the fitting parameters used for defining the relation between drying and wetting paths. The results of 25 cohesive and cohesionless soils indicated a coefficient of variation $(\mathrm{CV})$ of $56 \%$ for the air-entry value $\left(\psi_{b}\right)$. Phoon et al. (2010) [20] presented a probabilistic analysis of the SWCC based on the log-normal and shifted lognormal distributions of soils with different textures from the Unsaturated Soil Database, UNSODA (Nemes et al. 1993 [21]). A similar statistical evaluation was developed by Gitirana Jr. \& Fredlund (2016) [22] for the SWCC parameters (air-entry value, $\psi_{b}$; drainage slope, $\lambda_{d}$; and residual suction, $\left.\psi_{\text {res }}\right)$ and also for the hydraulic conductivity function parameters of 186 soils, including clays, loams and sands. Mishra et al. (1989) [23] analyzed 250 soils and pointed out that the direct measurement of the saturated hydraulic conductivity is highly preferable than its estimation due to the uncertainty in the predictions.

Zhai \& Rahardjo (2013) [24] quantified the uncertainty associated with fitting parameters of the Fredlund \& Xing (1994) [3] equation. They observed a

\footnotetext{
* Corresponding author: robertodutra@ discente.ufg.br
} 
high variability in the water content in the transition zone for a silty sand. According to Zhai et al. (2016) [25], the variability of unsaturated properties is significantly greater than that of saturated properties for the 59 materials studied.

There are only a few studies in the literature that specifically discuss the assessment of the variability of the PSD. Dubé et al. (2020) [26] analyzed the influence of different sampling techniques on the variability of PSD. The authors found an average CV of $5.28 \%$ for particle sizes less than $2 \mathrm{~mm}$ and $10.54 \%$ for a sieve opening of $4.75 \mathrm{~mm}$. Narizzano et al. (2008) [27] suggest that the mean variability of the PSD due to sampling is $4.77 \%$ for clays, gravels and sands.

Due to its central role as an input parameter of several SWCC prediction models, it is important to evaluate the variability of the PSD and how it contributes to uncertainties of the predicted SWCCs. Therefore, the key objective of this paper is to investigate the effects of the variability of the PSD in the SWCCs predicted using selected models from the literature; namely, Arya \& Paris (1981) [1], Fredlund et al. (2002) [4], Aubertin et al. 2003 [5], Wang et al. (2017) [8] and Alves et al. (2020) [9].

\section{Materials and methods}

\subsection{Materials}

Three glass beads (GBs) were selected in this study. Because these materials are spheres, the role of particle shape in the variability of the PSD curve can be considered relatively less complex. All the materials are relatively uniform, however, two of them are more uniform with a value of $C_{U}$ that is close to unity. The properties of these materials are shown in Table 1 and their physical characteristics are presented in Figure 1.

Table 1. Index properties of the glass beads (GB).

\begin{tabular}{cccc}
\hline Material & $\begin{array}{c}\text { Specific } \\
\text { gravity } \mathrm{G}_{\mathrm{s}}\end{array}$ & $\begin{array}{c}\text { Dry density, } \\
\rho_{\mathrm{d}}\left(\mathrm{g} / \mathrm{cm}^{3}\right)\end{array}$ & Porosity, $\mathrm{n}$ \\
\hline $\mathrm{GB} \# 1$ & 2.49 & 1.66 & 0.33 \\
$\mathrm{~GB} \# 2$ & 2.46 & 1.59 & 0.35 \\
$\mathrm{~GB} \# 3$ & 2.49 & 1.57 & 0.37 \\
\hline
\end{tabular}

\subsection{Determination of the PSD}

Three different methods are used for the determination of PSDs in this study. The first method is sieve analysis (SA), which is widely used and a standard technique in the determination the size of particle. This technique is simple; however, it is time consuming. The SA results produce a discrete distribution of particle sizes because of the openings of sieves that are limited to specific sizes. In addition, the SA results do not offer any information about the shape of the particles.

The second method used in the study is the laser diffraction (LD) which is based on diffraction patterns of a laser beam that is pointed to the particle. The method makes use of the intensity of the light scattered, which is directly proportional to the particle size (Beuselinck et al. 1998 [28], Yang et al. 2019 [29]).

The device used in the LD tests was the particle analyzer S3500 from Microtac. Ultrasonication was not necessary because the materials used in the study were glass beads with no aggregation between the particles. The accuracy and precision of the results are dependent on the specifications of the equipment. When ultrasound is not required, the tests usually take less than a minute. The sample mass was slightly wetted and homogenized prior to performing the tests to alleviate this limitation.
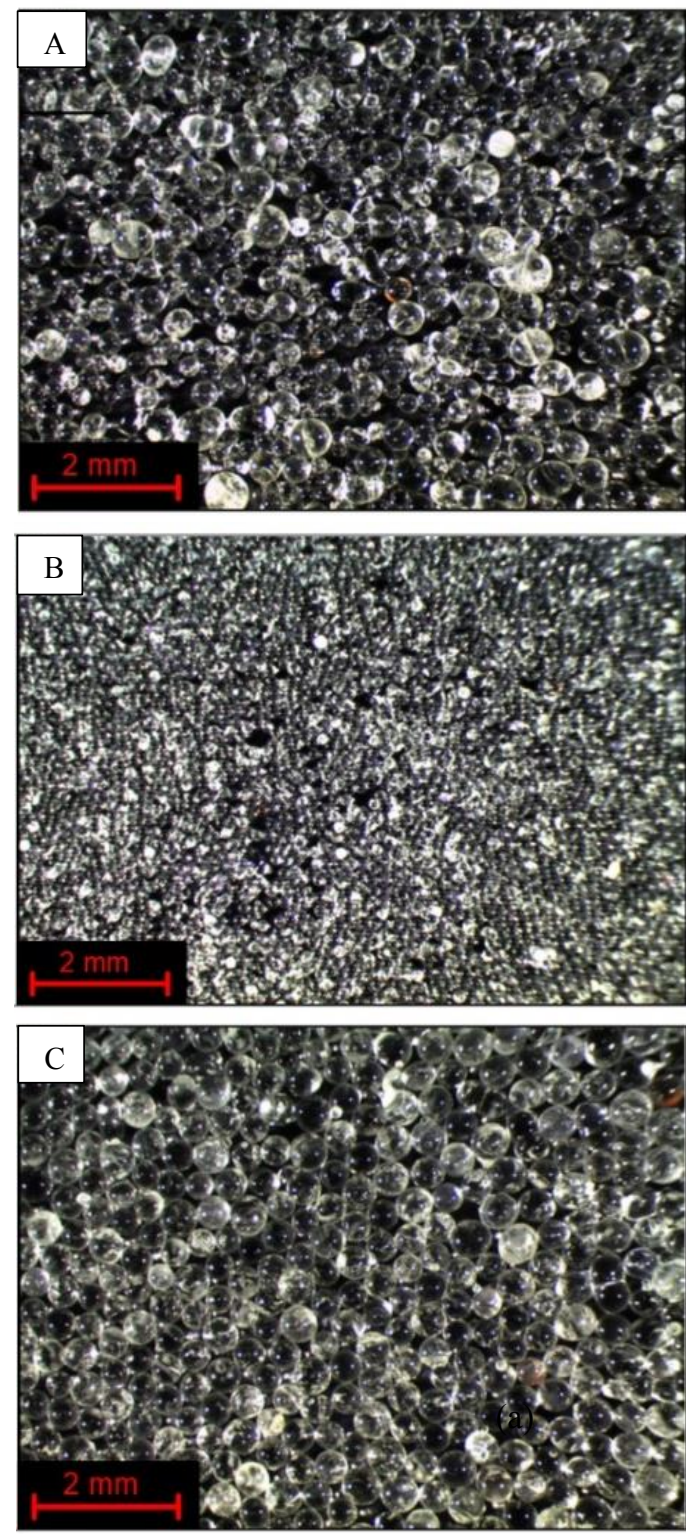

Fig. 1. Stereoscopic images of the glass beads: (a) GB \#1, (b) GB \#2, and (c) GB \#3.

The third method used for the determination of the PSD was based on image analysis (IA). This approach consists in taking a digital image of the sample and measure one or more geometrical characteristics of each particle. Some more complex image methods can provide information about the particles in three dimensions (Fernlund et al. 2007 [30], Wang et al. 2016 [31]). The images of the samples were obtained using a stereoscopic 
device (Leica MZ12-5). The samples were placed into a metallic recipient covered by a black opaque paper to avoid light reflection. Samples were slightly wetted to prevent segregation. Glass beads are transparent, making it more difficult to identify the particles boundaries when the particles are stacked. This inconvenience was overcome by placing the particles in a single layer on the paper.

The stereoscopic images of the materials are shown in Figure 1. After the images were taken, they were inserted into a CAD (Computer-Aid Design) software and the shape of the particles were replicated. The ImageJ software (Schindelin et al. 2012 [32]) was used to identify and measure the shape of the particles. Image J is an image processor able to execute several tasks including edition, processing, and analyzing. ImageJ was used to calculate the area of each particle. Mass-volume relationships allowed the determination of volume and the weight of the particles.

For each material, three laser diffractions and two image analyses were carried out. In addition, four sieve analyses were performed on GB \#1. The low $C_{\mathrm{U}}$ (close to 1) of materials GB \#2 and GB \#3 prevented the use of sieve analysis because of the unavailability of sieves with intermediate openings.

\subsection{Prediction methods}

Five methods summarized in Table 1 were used in the present study to predict the SWCCs of the three glass beads. The models of Arya \& Paris (1981) [1], Fredlund et al. (2002) [4] and Aubertin et al. (2003) [5] use the capillary bundle approximation to estimate at least one parameter of the SWCC. These models were originally tested by the authors for soils with different textures, ranging from sands to clays. These models present one or more empirical input parameters determined using specific soil databases.

Table 2. Summary of the models used to predict the SWCC.

\begin{tabular}{|c|c|c|c|c|}
\hline No. & Authors & Principle & $\begin{array}{l}\text { Soil } \\
\text { texture }\end{array}$ & $\begin{array}{l}\text { PSD } \\
\text { data }\end{array}$ \\
\hline$\# 1$ & $\begin{array}{l}\text { Arya \& Paris } \\
\text { (1981)[1] }\end{array}$ & \multirow{3}{*}{$\begin{array}{l}\text { Capillary } \\
\text { bundle model }\end{array}$} & \multirow{3}{*}{$\begin{array}{l}\text { Sands, } \\
\text { silts and } \\
\text { clays }\end{array}$} & $\begin{array}{l}\text { Entire } \\
\text { curve }\end{array}$ \\
\hline$\# 2$ & $\begin{array}{l}\text { Fredlund et } \\
\text { al. (2002)[4] }\end{array}$ & & & $\begin{array}{l}\text { Entire } \\
\text { Curve }\end{array}$ \\
\hline$\# 3$ & $\begin{array}{l}\text { Aubertin et } \\
\text { al. }(2003)[5]\end{array}$ & & & $\begin{array}{c}C_{\mathrm{U}}+ \\
D_{10}\end{array}$ \\
\hline \#4 & $\begin{array}{l}\text { Wang et al. } \\
\text { (2017)[8] }\end{array}$ & $\begin{array}{l}\text { Buckigham's } \\
\text { pi theorem }\end{array}$ & Sands & $\begin{array}{c}C_{\mathrm{U}}+ \\
D_{60}\end{array}$ \\
\hline$\# 5$ & $\begin{array}{l}\text { Alves et al. } \\
(2020)[9]\end{array}$ & $\begin{array}{l}\text { Pore-scale } \\
\text { model based } \\
\text { on unit cells }\end{array}$ & Sands & $\begin{array}{l}\text { Entire } \\
\text { Curve }\end{array}$ \\
\hline
\end{tabular}

The Wang et al. (2017) [8] and Alves et al. (2020) [9] models are suitable for coarse materials. The first is based on the dimensional analysis of Buckigham's pi theorem (Buckingham 1914 [33]) associated to the van Genuchten (1980) [34] equation. The Alves et al. (2020) [9] model takes into account of geometrical representation of the soil using the concept of unit cells and considering the particles as spheres. Wang et al. (2017) [8] model disregards specific gravity of the soil and does not use the residual water content as an input parameter. However, implementation of this model is quite simple. The Alves et al. (2020) [9] model is comparatively more difficult to implement; however, all the input parameters have physical meaning.

\subsection{Methods of data analysis}

Each PSD method results in curves with different quantities of pairs values of diameter and percentage passing $(\mathrm{d}, \% \mathrm{P})$. For instance, the SA of material GB \#1 presents eight pairs (corresponding to eight sieve size openings) while a single IA analysis produced 434 pairs of $\mathrm{d}$ and $\% \mathrm{P}$. Thus, to avoid bias in the manner how the PSDs are used, compared, and combined, only two parameters of the PSD curve were analyzed, namely: $D_{10}$ and $C_{\mathrm{U}}$. These two attributes were selected for the following reasons: i) $C_{\mathrm{U}}\left(D_{60} / D_{10}\right)$ is used as an input variable for the models of Aubertin et al. (2003) [5] and Wang et al. (2017) [8]; ii) the importance of finer particles represented by $D_{10}$ for the matric suction is wellrecognized (Lane \& Washburn 1946 [35], Peck et al. 1974 [36], Aubertin et al. 2003 [5], Torres 2011 [37], Wang et al. 2017 [8]). It is important to note that $C_{\mathrm{U}}$ is independent of $D_{10}$ because its definition involves both $D_{10}$ and $D_{60}$. However, $C_{\mathrm{U}}$ and $D_{10}$ may be statistically correlated.

The statistical analyses of the SWCC were performed using two different approaches, depending on how the PSD is used by the various prediction models. The first approach, used along with Arya \& Paris (1981) [1], Fredlund et al. (2002) [4] and Alves et al. (2020) [9] models, employs the log-normal distribution to calculate a confidence interval of $95 \%$ of the entire SWCC. The second method, used along with the models of Aubertin et al. (2003) [5] and Wang et al. (2017) [8], was based on a probabilistic Point Estimate Method, developed by Gitirana Jr. (2005) [38] and presented also by Franco et al. (2019) [39]. The method combines the Taylor series approximation and an univariated point estimate method. The method provides the statistical moments of selected variables (i.e., $\psi_{b}, \psi_{\text {res }}$ and $\theta_{\text {res }}$ ) as a function of the frequency distributions of the input variables $\left(D_{10}\right.$ and $C_{\mathrm{U}}$ ), including their correlation. In this study, it was assumed that $D_{10}$ and $C_{\mathrm{U}}$ present a log-normal distribution.

The scenarios used for the analysis of the variability propagated to the SWCC consisted in varying the value of each input variable (i.e., $C_{\mathrm{U}}$ and $D_{10}$ ) around its average value $(\mu)$ by adding or subtracting one standard deviation $(\sigma)$, resulting in the following combinations: $\left(D_{10+}, C_{\mathrm{U}}\right)$; $\left(D_{10-}, C_{\mathrm{U}}\right) ;\left(D_{10}, C_{\mathrm{U}+}\right) ;\left(D_{10}, C_{\mathrm{U}-}\right) ;\left(D_{10}, C_{\mathrm{U}}\right) ;\left(D_{10+}, C_{\mathrm{U}+}\right)$. The dispersion measures -(i.e., $\sigma$ and $\mathrm{CV}$ ) of material GB \#1 were extended to the other materials because of the limited data available, allowing higher statistical significance. To prevent physically inadmissible combinations for GB \#2 and \#3 such as $C_{\mathrm{U}}<1$, the logarithm of CV was used. 
For the models based on the entire PSD curve (Arya \& Paris 1981 [1]; Fredlund et al. 2002 [4]; Alves et al. 2020 [9]), it became necessary to fit the pairs $\left(D_{10}, C_{\mathrm{U}}\right)$ using the Fredlund et al. (2000) [40] equation, resulting in PSD curves that allowed the SWCC predictions.

The $\psi_{b}$ and the $\psi_{\text {res }}$ are key parameters that are useful in the interpretation of the SWCC and its variability. The $\psi_{b}$ is related to some of characteristics that can be derived from the PSD. The Aubertin el al. (2003) [7] model uses the $C_{\mathrm{U}}$ to estimate the $\psi_{b}$. The Haverkamp \& Parlange (1986) [4] model indirectly employ to the PSD to also calculate to $\psi_{b}$. The models of Arya \& Paris (1981) [3], Fredlund et al. (2002) [6] and Alves et al. (2020) [11] resort in the discretization of the PSD in order to calculate the corresponding discretized SWCC. The latter model describes the interactions between particles of different sizes by a correction factor also dependent of the $C_{\mathrm{U}}$.

In summary, the evaluation of the predicted SWCC was based on three characteristics, namely, the AEV $\left(\psi_{b}\right)$, the residual suction $\left(\psi_{\text {res }}\right)$ and its volumetric water content $\left(\theta_{\text {res }}\right)$. These parameters were calculated using the two-point method presented by Pham (2005) [41]. A total of 30 predicted SWCCs (6 combinations for 5 models) were generated.

\section{Results}

Figure 2 shows the PSD curves obtained using the different techniques of measurement of the particle sizes. For GB \#1, note that results of sieve analysis and laser diffraction are reasonably similar and both techniques underestimate the particle diameter in comparison to image analysis. Also, the two image analysis tests present differences under $50 \%$ of weight passing. Considering GB $\# 2$ and \#3, the results produce low variability among the techniques and the curves of each technique intersects at three distinct diameters. In this case, the difference between the results are higher for GB \#3.

Table 3 presents the statistical measures of $D_{10}$ and $C_{\mathrm{U}}$. For both parameters, the highest $\mathrm{CV}$ and standard error (SE) are observed for GB \#1 and those corresponding values of GB \#2 are approximately ten times lower.

Table 4 contains the descriptive statistics of the materials for each SWCC prediction model. The average values of the $\theta_{\text {res }}$ is $0.0071 \mathrm{~cm}^{3} / \mathrm{cm}^{3}$, which is relatively small probably because the adsorption of coarse-grained materials is relatively low. Thus, the following analyses of the statistics showed in Table 4 are focused on $\psi_{b}$ and $\psi_{\text {res }}$.

From the results summarized in Table 4 for $\psi_{b}$, it can be seen that Arya \& Paris (1981) [1] has a higher CV in comparison to the Fredlund et al. (2002) [4] model. This implies that the first model is the most sensitive to the variability of the PSD parameters. A possible explanation is that the Arya \& Paris (1981) [1] model required a significant discretization of the PSD curves because its equations produce incorrect values of matric suction in case of very narrow range between the pairs $(\mathrm{d}, \% \mathrm{P})$.
Table 3. Dispersion measures of the materials for $D_{10}$ and $C_{\mathrm{U}}$.

\begin{tabular}{cccc}
\hline Material & Measure & $D_{10}(\mathrm{~mm})$ & $C_{\mathrm{U}}$ \\
\hline & Mean & 0.201 & 2.152 \\
GB \#1 & Std. Dev. & 0.046 & 0.297 \\
& SE & 0.015 & 0.099 \\
& CV & $23.01 \%$ & $13.78 \%$ \\
\hline & Mean & 0.153 & 1.123 \\
GB \#2 & Std. Dev. & 0.004 & 0.016 \\
& SE & 0.002 & 0.007 \\
& CV & $2.41 \%$ & $1.41 \%$ \\
\hline & Mean & 0.383 & 1.125 \\
GB \#3 & Std. Dev. & 0.015 & 0.056 \\
& SE & 0.007 & 0.025 \\
& CV & $4.05 \%$ & $4.98 \%$ \\
\hline
\end{tabular}
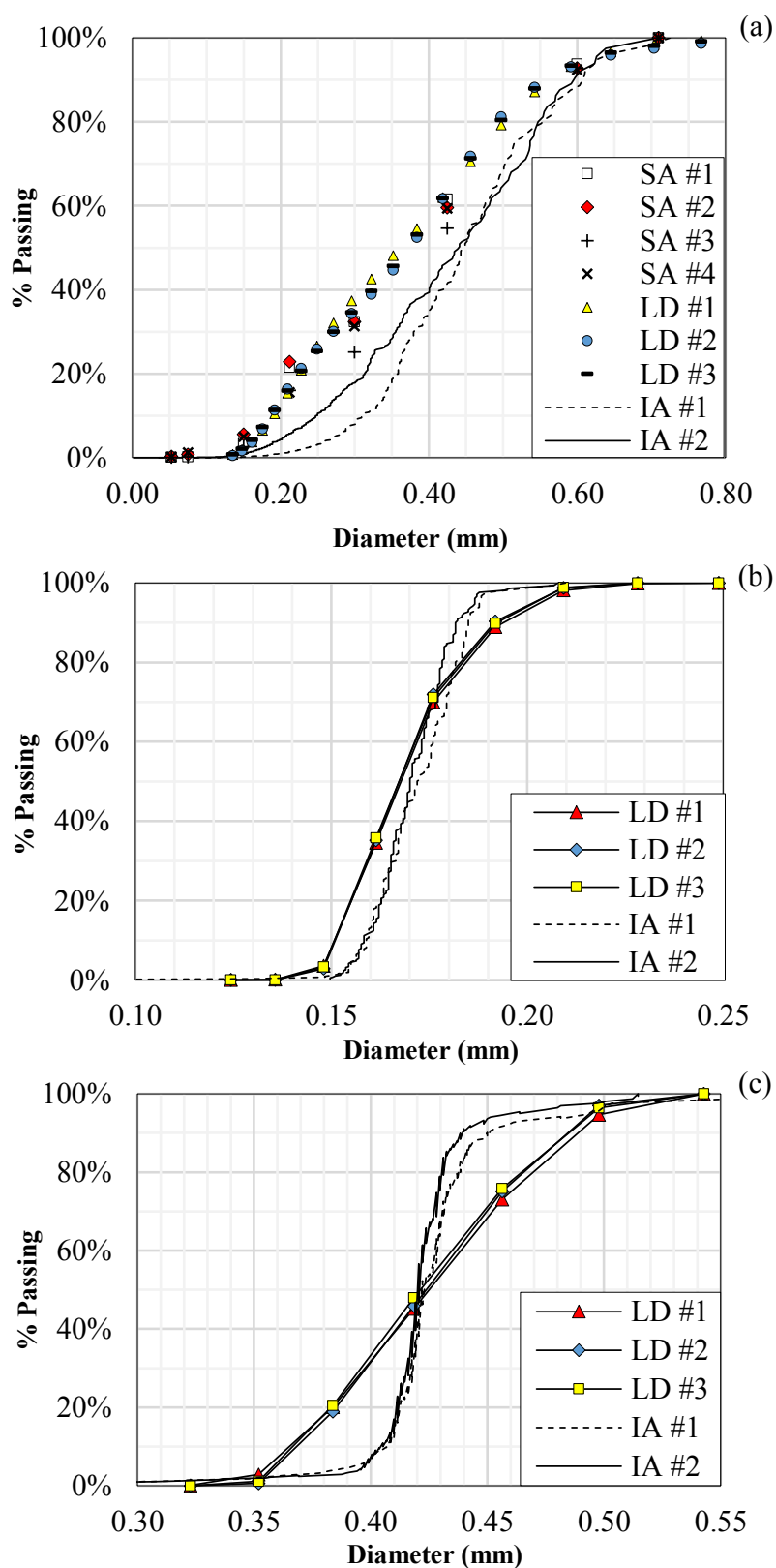

(c)

Fig. 2. PSD curves for the different methods - SA: Sieve Analysis; LD: Laser Diffraction; IA: Image Analysis - for the materials: (a) GB \#1; (b) GB \#2; and (c) GB \#3. 
Table 4. Descriptive statistics of the materials.

\begin{tabular}{|c|c|c|c|c|c|c|c|c|c|c|}
\hline \multirow{2}{*}{ Material } & \multirow{2}{*}{ Measure } & \multicolumn{3}{|c|}{$\psi_{b}(\mathrm{kPa})$} & \multicolumn{3}{|c|}{$\psi_{\text {res }}(\mathrm{kPa})$} & \multicolumn{3}{|c|}{$\theta_{\text {res }}$} \\
\hline & & GB \#1 & GB \#2 & GB \#3 & GB \#1 & GB \#2 & GB \#3 & GB \#1 & GB \#2 & GB \#3 \\
\hline \multirow{7}{*}{$\begin{array}{l}\text { Arya \& Paris } \\
(1981)[1]\end{array}$} & Min & 0.874 & 10.155 & 2.985 & (a) 9.568 & 11.217 & 3.248 & $1.39 \mathrm{E}-06$ & $1.65 \mathrm{E}-03$ & $2.73 \mathrm{E}-04$ \\
\hline & Max & 1.621 & 19.400 & 4.275 & 21.196 & 21.483 & 4.498 & $2.48 \mathrm{E}-04$ & $1.59 \mathrm{E}-02$ & $7.43 \mathrm{E}-03$ \\
\hline & Median & 1.099 & 11.321 & 3.257 & 13.800 & 13.614 & 3.875 & $1.48 \mathrm{E}-06$ & 8.81E-03 & $3.75 \mathrm{E}-03$ \\
\hline & Mean & 1.200 & 12.672 & 3.398 & 14.561 & 15.041 & 3.903 & 5.07E-05 & $8.84 \mathrm{E}-03$ & $3.56 \mathrm{E}-03$ \\
\hline & Std. Dev. & 0.342 & 3.794 & 0.504 & 4.229 & 3.984 & 0.499 & $1.10 \mathrm{E}-04$ & $5.98 \mathrm{E}-03$ & $2.68 \mathrm{E}-03$ \\
\hline & SE & 0.153 & 1.697 & 0.225 & 1.891 & 1.782 & 0.223 & 0.000 & 0.003 & 0.001 \\
\hline & $\mathrm{CV}$ & $28.5 \%$ & $29.9 \%$ & $14.8 \%$ & $29.0 \%$ & $26.5 \%$ & $12.8 \%$ & $217.1 \%$ & $67.7 \%$ & $75.2 \%$ \\
\hline \multirow{7}{*}{$\begin{array}{l}\text { Fredlund et al. } \\
(2002)[4]\end{array}$} & Min & 0.654 & 1.419 & 0.760 & 1.284 & 2.726 & 1.219 & 2.14E-02 & 8.73E-04 & $1.12 \mathrm{E}-02$ \\
\hline & Max & 1.096 & 1.668 & 0.962 & 1.932 & 9.997 & 1.503 & $2.70 \mathrm{E}-02$ & $6.60 \mathrm{E}-03$ & $1.33 \mathrm{E}-02$ \\
\hline & Median & 0.800 & 1.590 & 0.838 & 1.570 & 4.897 & 1.306 & $2.47 \mathrm{E}-02$ & $2.40 \mathrm{E}-03$ & $1.20 \mathrm{E}-02$ \\
\hline & Mean & 0.854 & 1.570 & 0.858 & 1.553 & 5.504 & 1.324 & $2.47 \mathrm{E}-02$ & $3.48 \mathrm{E}-03$ & $1.20 \mathrm{E}-02$ \\
\hline & Std. Dev. & 0.180 & 0.091 & 0.079 & 0.265 & 2.688 & 0.108 & 2.39E-03 & $2.64 \mathrm{E}-03$ & $9.00 \mathrm{E}-04$ \\
\hline & SE & 0.080 & 0.041 & 0.035 & 0.119 & 1.202 & 0.048 & 0.001 & 0.001 & 0.000 \\
\hline & $\mathrm{CV}$ & $21.0 \%$ & $5.8 \%$ & $9.2 \%$ & $17.1 \%$ & $48.8 \%$ & $8.2 \%$ & $9.7 \%$ & $75.7 \%$ & $7.5 \%$ \\
\hline \multirow{7}{*}{$\begin{array}{l}\text { Aubertin et al. } \\
(2003)[5]\end{array}$} & Min & 0.844 & 1.658 & 0.704 & 2.869 & 5.587 & 2.268 & $1.68 \mathrm{E}-02$ & $1.39 \mathrm{E}-02$ & $1.12 \mathrm{E}-02$ \\
\hline & Max & 1.351 & 2.661 & 0.896 & 4.552 & 8.764 & 2.877 & 2.32E-02 & $2.50 \mathrm{E}-02$ & $1.33 \mathrm{E}-02$ \\
\hline & Median & 1.037 & 2.101 & 0.820 & 3.599 & 7.022 & 2.477 & $1.93 \mathrm{E}-02$ & $2.00 \mathrm{E}-02$ & $1.20 \mathrm{E}-02$ \\
\hline & Mean & 1.060 & 2.125 & 0.801 & 3.651 & 7.079 & 2.545 & $1.96 \mathrm{E}-02$ & $1.94 \mathrm{E}-02$ & $1.20 \mathrm{E}-02$ \\
\hline & Std. Dev. & 0.203 & 0.357 & 0.076 & 0.618 & 1.128 & 0.231 & $2.63 \mathrm{E}-03$ & $4.52 \mathrm{E}-03$ & $9.00 \mathrm{E}-04$ \\
\hline & SE & 0.091 & 0.160 & 0.034 & 0.276 & 0.505 & 0.103 & 0.001 & 0.002 & 0.000 \\
\hline & $\mathrm{CV}$ & $19.1 \%$ & $16.8 \%$ & $9.4 \%$ & $16.9 \%$ & $15.9 \%$ & $9.1 \%$ & $13.4 \%$ & $23.3 \%$ & $7.5 \%$ \\
\hline \multirow{7}{*}{$\begin{array}{l}\text { Wang et al. } \\
\text { (2017)[8] }\end{array}$} & Min & 0.981 & 3.515 & 1.574 & 3.356 & 4.616 & 2.074 & $5.43 \mathrm{E}-05$ & $6.78 \mathrm{E}-11$ & $1.78 \mathrm{E}-15$ \\
\hline & Max & 1.567 & 5.611 & 1.994 & 5.327 & 7.397 & 2.641 & $2.91 \mathrm{E}-03$ & $1.60 \mathrm{E}-06$ & $9.11 \mathrm{E}-04$ \\
\hline & Median & 1.209 & 4.442 & 1.771 & 4.147 & 5.798 & 2.319 & $8.16 \mathrm{E}-04$ & $6.59 \mathrm{E}-08$ & $6.58 \mathrm{E}-06$ \\
\hline & Mean & 1.248 & 4.538 & 1.798 & 4.211 & 5.880 & 2.334 & $1.36 \mathrm{E}-03$ & $3.66 \mathrm{E}-07$ & $3.09 \mathrm{E}-04$ \\
\hline & Std. Dev. & 0.270 & 0.761 & 0.165 & 0.712 & 0.991 & 0.202 & $1.25 \mathrm{E}-03$ & $6.93 \mathrm{E}-07$ & $4.32 \mathrm{E}-04$ \\
\hline & SE & 0.121 & 0.340 & 0.074 & 0.318 & 0.443 & 0.090 & 0.001 & 0.000 & 0.000 \\
\hline & $\mathrm{CV}$ & $21.6 \%$ & $16.8 \%$ & $9.2 \%$ & $16.9 \%$ & $16.8 \%$ & $8.7 \%$ & $91.8 \%$ & $189.2 \%$ & $139.8 \%$ \\
\hline \multirow{7}{*}{$\begin{array}{l}\text { Alves et al. } \\
(2020)[9]\end{array}$} & Min & 1.137 & 2.292 & 1.149 & 5.272 & 3.709 & 1.480 & $1.00 \mathrm{E}-09$ & $3.07 \mathrm{E}-05$ & $6.37 \mathrm{E}-05$ \\
\hline & Max & 1.820 & 3.664 & 1.446 & 8.433 & 5.931 & 1.877 & $1.62 \mathrm{E}-04$ & $1.72 \mathrm{E}-03$ & $1.34 \mathrm{E}-03$ \\
\hline & Median & 1.302 & 2.906 & 1.171 & 6.815 & 4.651 & 1.869 & $9.34 \mathrm{E}-05$ & $6.93 \mathrm{E}-05$ & $9.37 \mathrm{E}-04$ \\
\hline & Mean & 1.399 & 2.937 & 1.249 & 6.744 & 4.720 & 1.776 & 8.64E-05 & $6.66 \mathrm{E}-04$ & $7.38 \mathrm{E}-04$ \\
\hline & Std. Dev. & 0.282 & 0.487 & 0.130 & 1.203 & 0.791 & 0.171 & $6.40 \mathrm{E}-05$ & 8.53E-04 & $6.22 \mathrm{E}-04$ \\
\hline & SE & 0.126 & 0.218 & 0.058 & 0.538 & 0.354 & 0.076 & 0.000 & 0.000 & 0.000 \\
\hline & $\mathrm{CV}$ & $20.1 \%$ & $16.6 \%$ & $10.4 \%$ & $17.8 \%$ & $16.8 \%$ & $9.6 \%$ & $74.1 \%$ & $128.0 \%$ & $84.4 \%$ \\
\hline
\end{tabular}

For GB \#1 and \#3, the CVs of all models are quite similar (average of 20.5 and $9.6 \%$, respectively), except for the Arya \& Paris (1981) [1]. This means that the variability of the PSD affected in a similar manner the variability of the predicted values of $\psi_{b}$, regardless of the prediction model. For GB \#2, the same behavior is presented except for the Fredlund et al. (2002) [4] model. Zapata et al. (2000) [18] verified the variability of a sandy soil using three SWCC prediction models based on soil index properties. For the $\psi_{b}$, the authors found a mean variability of $24.7 \%$ which is greater than the mean CV
$(16.6 \%)$ of the three materials used in this study. Nevertheless, this scenario is different for the residual suction. In this case, the authors obtained a mean $\mathrm{CV}$ of $2.7 \%$ against the $54.2 \%$ demonstrated in Table 4 .

Figure 3 depicts the variability of the predicted SWCCs for the models that rely on the entire SWCC (Arya \& Paris 1981 [1], Fredlund et al. 2002 [4] and Alves et al. 2020 [9]) using a log-normal distribution. The confidence interval (CI) adopted was $95 \%$. The plot in the semi-logarithmic scale shows that GB \#1 presents a variability of $\psi_{b}$ lower than the variability of $\psi_{\text {res }}$, 
contrary to the behavior showed by GB \#2 and \#3. This trend was not observed in Table 4. However, considering that Gitirana Jr. \& Fredlund (2016) [22] pointed out that the log-normal distribution is adequate to represent the $\psi_{b}$ and the $\psi_{\text {res }}$, it is noticeable that different statistics approaches can lead to different conclusions. Close examination of the results summarized in Table 3 and Figure 3 , suggests that the influence of $D_{10}$ in $\psi_{b}$ decreases with an increase in $C_{\mathrm{U}}$. This argument is supported by comparing the average value of $C_{U}$ and the range corresponding to a $95 \%$ confidence interval of $\psi_{b}$ where it is possible to notice that the $C_{\mathrm{U}}$ and the variability of $\psi_{b}$ are inversely correlated.

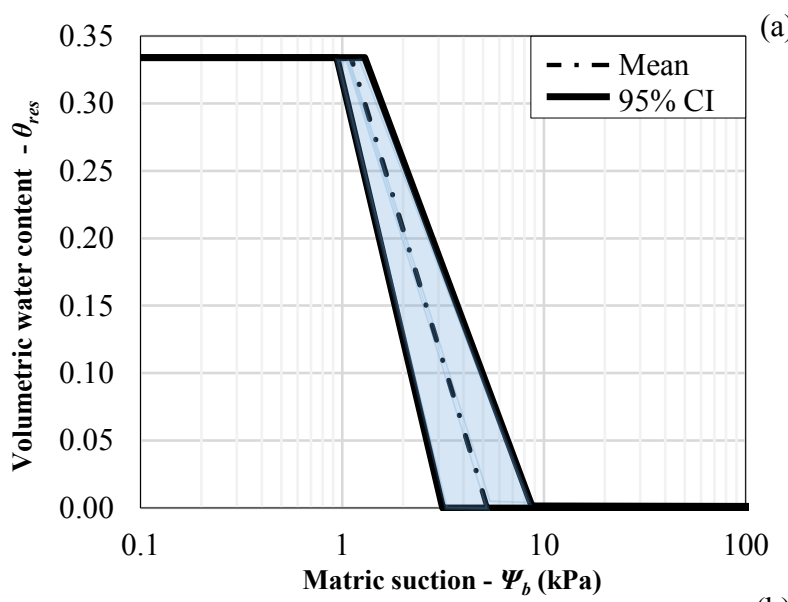

(b)
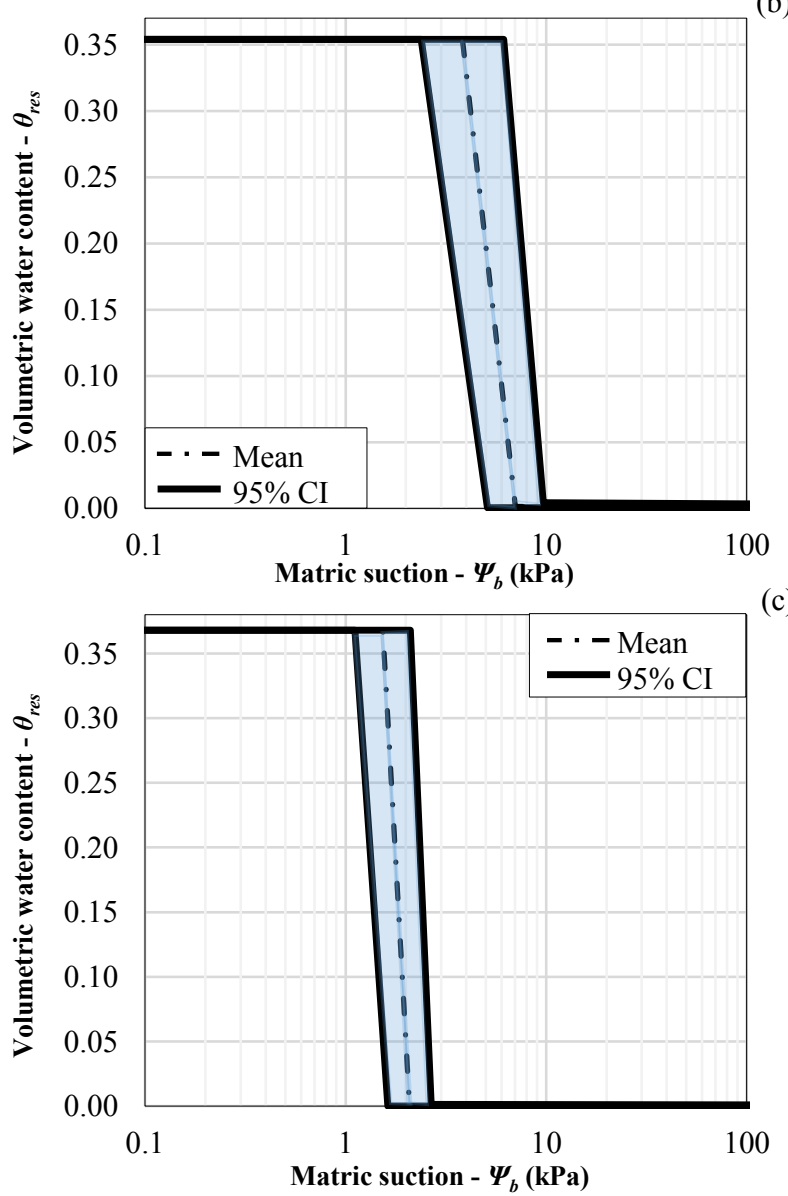

Fig. 3. Confidence interval (CI) of the predicted SWCCs for the models of Arya \& Paris (1981) [1], Fredlund et al. (2002) [4] and Alves et al. (2020) [9]: (a) GB \#1; (b) GB \#2; and (c) GB \#3.
Table 5 demonstrates the statistical analyses for the models of Aubertin et al. (2003) [5] and Wang et al. (2017) [8] using the probabilistic method developed by Gitirana Jr. (2005) [40]. Similarly, as summarized in Table 4, the values of residual volumetric water content are relatively low and are going to be neglected in the analyses presented herein. In general, the $\mathrm{CV}$ values indicate that the $\psi_{b}$ is more sensitive to changes in the PSD curve than the $\psi_{\text {res }}$. The probabilistic analysis results show greater variability for GB \#2.

Table 5. Dispersion measures of the materials for Aubertin et al. (2003) [5] and Wang et al. (2017) [8] models.

\begin{tabular}{ccccc}
\hline \multirow{2}{*}{ Parameter } & Measure & \multicolumn{3}{c}{ Material } \\
\cline { 3 - 5 } & & GB \#1 & GB \#2 & GB \#3 \\
\hline \multirow{4}{*}{$\psi_{b}$} & Mean & 1.293 & 3.328 & 1.282 \\
& Std. Dev. & 0.287 & 0.839 & 0.189 \\
& SE & 0.083 & 0.242 & 0.055 \\
& CV & $22.2 \%$ & $25.2 \%$ & $14.7 \%$ \\
\hline \multirow{4}{*}{$\psi_{\text {res }}$} & Mean & 4.369 & 6.335 & 2.504 \\
& Std. Dev. & 0.748 & 1.438 & 0.294 \\
& SE & 0.216 & 0.415 & 0.085 \\
$\theta_{\text {res }}$ & CV & $17.1 \%$ & $22.7 \%$ & $11.7 \%$ \\
\hline \multirow{4}{*}{} & Mean & 0.018 & 0.007 & 0.008 \\
& Std. Dev. & 0.000 & 0.002 & 0.000 \\
& SE & 0.000 & 0.001 & 0.000
\end{tabular}

Figures 4 and 5 present probabilistic tornado diagrams of the $\psi_{b}$ and the $\psi_{\text {res }}$, respectively. These diagrams demonstrate the sensibility of the output parameters to each specific input variable. The closer the size of a bar is to that of the "full model", the less sensitive is the output variable to the corresponding input parameters. According to Figure $4, \psi_{b}$ is more sensitive to $D_{10}$, suggesting a better correlation between the $\psi_{b}$ and $D_{10}$. The odd behavior presented by Figures 5(a) and (b) showing the $C_{\mathrm{U}}$ bar wider than the "full-model" bar is caused by the negative correlation between $D_{10}$ and $C_{\mathrm{U}}$ (- 0.952$)$. Figure 5 also shows that the variability of $D_{10}$ affects significantly the $\psi_{\text {res }}$ when compared to $C_{\mathrm{U}}$. Therefore, it seems that $D_{10}$ has a major role for both the transition and residual stages of the predicted SWCCs.

\section{Conclusions}

The influence of the variability in the PSD on the predicted SWCCs was evaluated using the methods of Arya \& Paris (1981) [1], Fredlund et al. 2002 [4], Aubertin et al. 2003 [5], Wang et al. 2017 [8] and Alves et al. 2020 [9] for the PSD of three glass beads. Sieves analysis, laser diffraction and image analysis composed the techniques to obtain the PSD curves. Among the five models, the Arya \& Paris (1981) [1] resulted in the greatest variability propagation, probably due to the influence of the discretization of the PSD curve. 

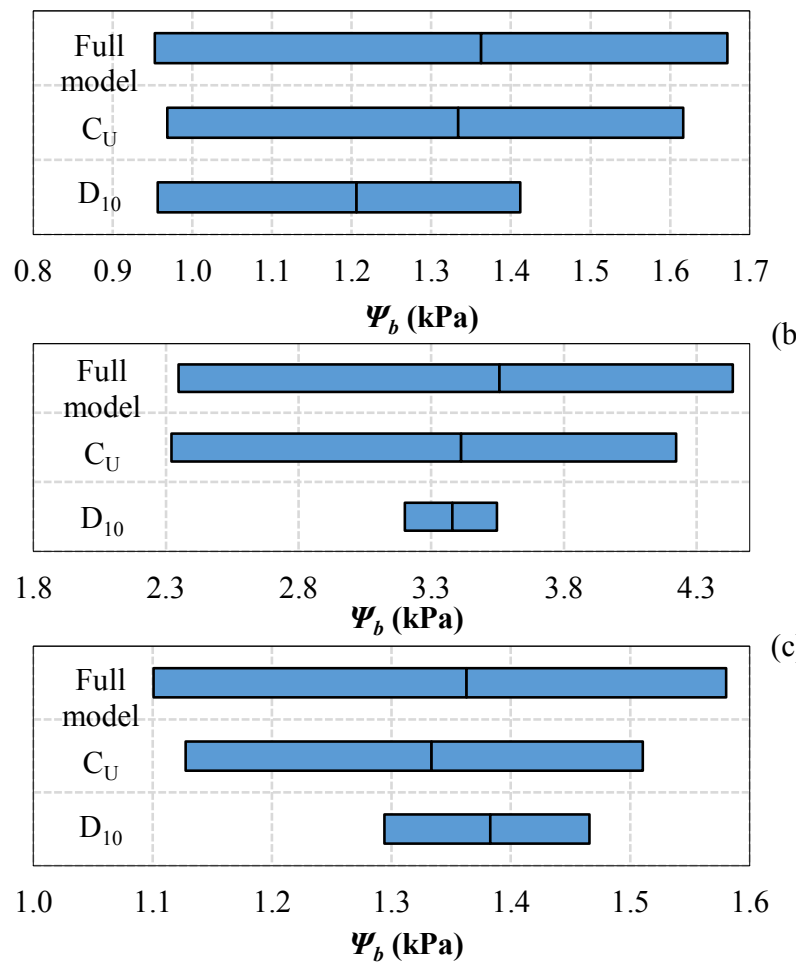

Fig. 4. Probabilistic event tornado diagrams for $\psi_{b}$ : (a) GB \#1; (b) GB \#2; and (c) GB \#3.

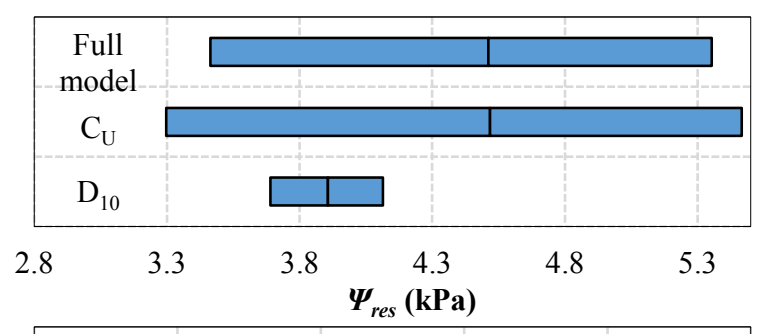

(a)
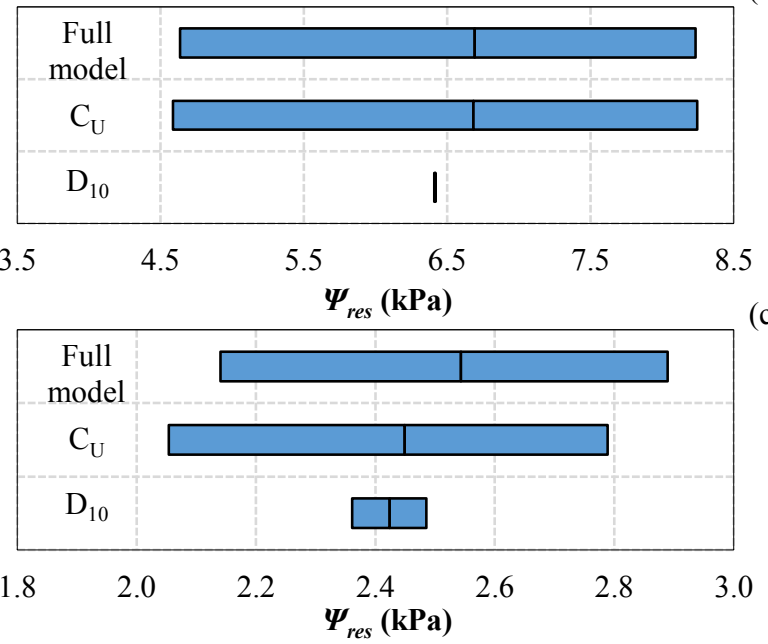

Fig. 5. Probabilistic event tornado diagrams for $\psi_{\text {res }}$ : (a) GB \#1; (b) GB \#2; and (c) GB \#3.

The variability for the other models were, in general, reasonable akin. The results demonstrated that both $\psi_{b}$ and $\psi_{\text {res }}$ present variabilities with sensitivity to variations in $D_{10}$ and $C_{\mathrm{U}}$. Overall, the variations in the SWCC parameters are usually similar in magnitude of those presented by $D_{10}$ and $C_{\mathrm{U}}$. The $C_{\mathrm{U}}$ seems to be more related to $\psi_{\text {res }}$ while $D_{10}$ sound to affect more significantly the $\psi_{b}$, however, the $D_{10}$ appears to have an important role for all ranges of matric suction.

This study demonstrates that the PSD is quite important for the predicted SWCCs which are related to the accuracy of the techniques for the PSD measurement. Studies using natural coarse-grained materials and soils with fines are necessary to complement the results and investigate the variability related to the adsorbed water.

\section{Acknowledgements}

The authors would like to thank Eletrobrás FURNAS for the support provided and Agência Nacional de Energia Elétrica (ANEEL) for supporting this research (PDANEEL 0394-1705/2017).

\section{References}

1. L. M. Arya \& J. F. Paris. (1981). A physicoempirical model to predict the soil moisture characteristic from particle-size distribution and bulk density data. Soil Sci. Soc. Am. J. 45, 1023-1030, doi: 10.2136/sssaj1981.03615995004500060004x

2. R. Haverkamp \& J. Y. Parlange. (1986). Predicting the water-retention curve from particle-size distribution: sands soils without organic matter. Soil Sci. 142(6), 325-339

3. D. G. Fredlund \& A. Xing. (1994). Equations for the soil-water characteristic curve. Can. Geo. J. 31(3), 521-532. doi: 10.1139/t94-061

4. M. D. Fredlund, G. W. Wilson \& D. G. Fredlund. (2002). Use of the grain-size distribution for estimation of the soil-water characteristic curve. Can. Geo. J. 39, 1103-1117, doi: 10.1139/T02-049

5. M. Aubertin, M. Mbonimpa, B. Bussière \& R. P. Chapuis. (2003). A model to predict the water retention curve from basic geotechnical properties. Can. Geo. J. 40, 1104-1122, doi: 10.1139/t03-054

6. M. Tuller \& D. Or. (2005). Water films and scaling of soil characteristic curves at low water contents. Water Res. Res. 41, 6, doi: 10.1029/2005WR004142

7. R. Jaafar \& W. J. Likos. (2011). Estimating water retention characteristics of sands from grain size distribution using idealized packing conditions. Geo. Test. J. 34(5), 1-14, doi: 10.1520/GTJ103594

8. J. Wang, N. Hu, B. Fraçois \& P. Lambert. (2017). Estimating water retention curves and strength properties of unsaturated sandy soils from basic soil gradation parameters. Water Res. Res. 53(7), 60696088, doi: 10.1002/2017WR020411

9. R. D. Alves, G. F. N. Gitirana Jr. \& S. K. Vanapalli. (2020). Advances in the modeling of the soil-water characteristic curve using pore-scale analysis. Comp. Geo. 127, 12, doi: 10.1016/j.compgeo.2020.103766

10. D. G. Fredlund, H. Rahardjo \& M. D. Fredlund. (2012). Unsaturated soil mechanics in engineering practice (John Wiley, New Jersey).

11. N. Lu \& W. J. Likos. (2004). Unsaturated soil mechanics (John Wiley, New Jersey).

12. N. B. Vargaftik, B. N. Volkov \& L. D. Voljak. (1983). International tables of the surface tension of 
water. J. Phys. Chem. Ref. Data. 12(3), 817-820, doi: $10.1063 / 1.555688$

13. A. Karangunduz, K. D. Pennell \& M. H. Young. (2001). Influence of a nonionic surfactant on the water retention properties of unsaturated soils. Soil Sci. Soc. Am. J. 65, 1392-1399, doi: 10.2136/sssaj2001.6551392x

14. N. Sghaier, M. Prat \& S. B. Nasrallah. (2006). On the influence of sodium chloride concentration on equilibrium contact angle. Chem. Eng. J. 122, 47-53, doi: 10.1016/j.cej.2006.02.017

15. S. C. Gupta \& W. E. Larson. (1979). Estimating soil water retention characteristics from particle size distribution, organic matter percent, and bulk density. Water Res. Res. 15(6), 1633-1635, doi: 10.1029/WR015i006p01633

16. R. Jong, C. A. Campbell \& W. Nicholaichuk. (1983). Water retention equations and their relationship to soil organic matter and particle size distribution for disturbed samples. Can. J. Soil Sci. 63, 291-302, doi: 10.4141/cjss83-029

17. Z. Liu, X. Yu \& L. Wan. (2014). Capillary rise method for the measurement of the contact angle of soils. Acta Geotech. 11, 21-35, doi: 10.1007/s11440014-0352-x

18. C. E. Zapata, W. N. Houston, S. L. Houston, K. D. Walsh. (2000). Soil-water characteristic curve variability. Geo-Denver, Denver, 84-124, doi: $10.1061 / 40510(287) 7$

19. W. J. Likos, N. Lu \& J. W. Godt. (2013). Hysteresis and uncertainty in soil water-retention curve parameters. J. Geotech. Geoenv. Eng. 140(14), 12p, doi: 10.1061/(ASCE)GT.1943-5606.0001071

20. K. K. Phoon, A. Santoso \& S. T. Quek. (2010). Probabilistic analysis of soil-water characteristic curve. J. Geotech. Geoenv. Eng. 136(3), 445-455, doi: 10.1061/(ASCE)GT.1943-5606.0000222

21. A. Nemes, M. Schaap, F. J. Leij \& J. H. M. Wösten. (1993). UNSODA 2.0: Unsaturated Soil Hydraulic Database, US Salinity Laboratory - ARS - USDA, doi: 10.15482/USDA.ADC/1173246

22. G. F. N. Gitirana Jr. \& D. G. Fredlund. (2016). Statistical assessment of hydraulic properties of unsaturated soils. Soils and Rocks 39(1), 81-95, doi: 10.28927/SR.39181

23. S. Mishra, J. C. Parker \& N. Singhal. (1989). Estimation of soil hydraulic properties and their uncertainty from particle size distribution data. J. Hydrology. 108, 1-18, doi: 10.1016/00221694(89)90275-8

24. Q. Zhai \& H. Rahardjo. (2013). Quantification of uncertainties in soil-water characteristic curve associated with fitting parameters. Eng. Geol. 163, 144-152, doi: 10.1016/j.enggeo.2013.05.014

25. Q. Zhai, H. Rahardjo \& A. Satyanaga (2016). Variability in unsaturated hydraulic properties of residual soil in Singapore. Eng. Geol. 209, 21-29, doi: 10.1016/j.enggeo.2016.04.034

26. J. S. Dubé, J. Ternisien, J. P. Boudreault, F. Duhaime \& Y. Éthier. (2020). Variability in particle size distribution due to sampling. Geo. Test. J. 27, doi: 10.1520/GTJ20190030
27. R. Narizzano, F. Risso, R. Innocenti, V. Mollica \& B. Tortarolo. (2008). Soil subsampling in environmental sciences: the role of granulometry. J. Environ. Monit. 10, 993-997, doi: 10.1039/b806522p

28. L. Beuselinck, G. Govers, J. Poesen, G. Degraer \& L. Froyen. (1998). Grain-size analysis by laser diffractometry: comparison with the sieve-pipette method. Catena, 32, 193-208, doi: 10.1016/S03418162(98)00051-4

29. Y. Yang, L. Wang, O. Wendroth, B. Liu, C. Cheng, T. Huang \& Y. Shi. (2019). Is the laser diffraction method reliable for soil particle size distribution analysis? Soil. Sci. Soc. Am. J. 12, doi: 10.2136/sssaj2018.07.0252

30. J. M. R. Fernlund, R. W. Zimmerman \& D. Kragic. (2007). Influence of volume/mass on grain-size curves and conversion of image-analysis size to sieve size. Eng. Geol. 90, 124-137, doi: 10.1016/j.enggeo.2006.12.007

31. Y. Wang, C. L. Lin \& J. D. Miller. (2016). 3D image segmentation for analysis of multisize particles in a packed particle bed. Power Tech. 301, 160-168, doi: 10.1016/j.powtec.2016.05.012

32. J. Schindelin, I. Arganda-Carreras, E. Frise, V. Kaynig, M. Longair, T. Pietzsch et al. (2012). Fiji: an open-source platform for biological-image analysis. Nat. Meth. 9(7), 676-682, doi:10.1038/nmeth.2019

33. E. Buckingham. (1914). On physically similar systems; illustrations of the use of dimensional equations. Phys. Rev. IV(4), 345-376, doi: 0.1103/PhysRev.4.345

34. M. T. van Genuchten. (1980). A closed-form equation for predicting the hydraulic conductivity of unsaturated soils. J. Soil Sci. Soc. Am. 44, 892-898. doi: $10.2136 /$ sssaj1980.03615995004400050002x

35. K. S. Lane, \& S. E. Washburn. (1946). Capillary tests by capillarimeters and by soil filled tubes. Proceedings of Highway Research Board, 26, 460473.

36. R. B. Peck, W. E. Hansen \& T. H. Thornburn. (1974). Foundation Engineering (Wiley, New York).

37. G. H. Torres. (2011). Estimating the soil-water characteristic curve using grain-size analysis and plasticity index. M.Sc. Thesis (Arizona State University, Tempe, AZ)

38. G. F. N. Gitirana Jr. (2005). Weather-related geohazard assessment model for railway embankment stability. PhD Thesis (University of Saskatchewan, Canada), 411p.

39. V. H. Franco, G. F. N. Gitirana Jr. \& A. P. de Assis. (2019). Probabilistic assessment of tunnelinginduced building damage. Comp. Geotech. 113, 15p, doi: 10.1016/j.compgeo.2019.103097

40. M. D. Fredlund, D. G. Fredlund \& G. W. Wilson. (2000). An equation to represent grain-size distribution. Can. Geo. J. 37(4), 817-827, doi: 10.1139/t00-015

41. H. Q. Pham, D. G. Fredlund \& S. L. Barbour. (2005). A study of hysteresis models for soil-water characteristic curve. Can. Geotech. J. 42(6), 15481568, doi: 10.1139/t05-071 